\title{
Gastrointestinal Microbiota and Some Children Diseases: A Review
}

\author{
Thabata Koester Weber and Isabel Polanco \\ Department of Paediatric Gastroenterology and Nutrition, Children's University Hospital "La Paz", Autonomous University of Madrid, \\ Paseo de la Castellana 261, 28046 Madrid, Spain \\ Correspondence should be addressed to Isabel Polanco, ipolanco.hulp@salud.madrid.org
}

Received 30 March 2012; Revised 28 July 2012; Accepted 30 July 2012

Academic Editor: Bjørn Moum

Copyright (๑) 2012 T. K. Weber and I. Polanco. This is an open access article distributed under the Creative Commons Attribution License, which permits unrestricted use, distribution, and reproduction in any medium, provided the original work is properly cited.

The bacterial colonization is defined immediately after birth, through direct contact with maternal microbiota and may be influenced during lactation. There is emerging evidence indicating that quantitative and qualitative changes on gut microbiota contribute to alterations in the mucosal activation of immune system leading to intra- or extra-intestinal diseases. A balance between pathogenic and beneficial microbiota throughout childhood and adolescence is important to gastrointestinal health, including protection against pathogens, inhibition of pathogens, nutrient processing (synthesis of vitamin $\mathrm{K}$ ), stimulation of angiogenesis, and regulation of host fat storage. Probiotics can promote an intentional modulation of intestinal microbiota favoring the health of the host. This paper is a review about modulation of intestinal microbiota on prevention and adjuvant treatment of pediatric gastrointestinal diseases.

\section{Composition and Function of Gastrointestinal Microbiota}

The microbiota of the human gastrointestinal tract inhabits a complex ecosystem [1]. Normally it is obtained by newborn after birth and suffers influences on the type of delivery and contamination from the environment [2]. At birth, the gastrointestinal tracts are immature and their development continues during the first years of life [3]. During this period, other factors may also influence the colonization of bacteria in the gastrointestinal tract such as the type of milk-feeding (breast-feeding or "formula-feeding") and possibly genetic characteristics (genotype) [3-5].

Facultative anaerobic bacteria, as Enterobacteria, Enterococci, and Streptococci, dominate the first stage of colonization, within a week following birth. After this early stage, these proportions are reversed and the number of strictly anaerobic bacteria, such as Bifidobacteria, Bacteroides, and Clostridia, begins to exceed the number of facultative anaerobes bacteria [6]. The commensal bacteria play a substantial role in regulating gut homeostasis [7].
An adequate gut microbial colonization process contributes to the physiological development of the gut and the maturation of the immune system, thereby determining the risk of developing disease later in life [6]. According to Roberfroid et al. [1], several factors can influence the number and diversity of bacteria present in different regions of the gastrointestinal tract. The main factors contributing to variety of bacteria are $\mathrm{pH}$, peristalsis, nutrient availability, oxidation-reduction potential within the tissue, age of host, host health, bacterial adhesion, bacterial cooperation, mucus secretions containing immunoglobulin, bacteria antagonism, and transit time [1].

In stomach, the bacterial load is low in healthy individuals. The predominant organisms isolated include Lactobacilli, streptococci, and yeasts $[8,9]$. In the duodenum (small intestine) the environment is acidic ( $\mathrm{pH}$ between 4 and 5), predominating Lactobacilli and Streptococci. In healthy individuals, the number of bacteria in the duodenum is higher than found in the stomach, approximately $10^{2}-$ $10^{4}$ colony forming unit versus $10^{2} \mathrm{CFU}$. The microbiota changes strongly from the duodenum to the ileum, as 
the velocity of the intraluminal content decreases and $\mathrm{pH}$ increases, increasing bacterial loads to $10^{6}-10^{8} \mathrm{CFU}$. The colon microbiota population reaches $10^{10}-10^{12} \mathrm{CFU}[8]$; an adult may have around $10^{14} \mathrm{CFU}$, outnumbering the total eukaryotic cells in the human body [10].

In this context, there are two factors associated with the greatest physiological colonization in the large intestine: neutral $\mathrm{pH}$ and higher transit time. Studies showed that the mean of colonic transit time in pediatric patients without motility disorders is approximately 30 hours [11, 12], higher than in the small intestine, where the transit varies from 2 to 4 hours [1].

The main function of the intestinal microbiota is to limit the growth of potential pathogenic microorganisms, preventing the invasion and implementation of these microorganisms on ecosystem. In addition, the microbiota, competes for space and has the capacity to secrete antimicrobial substances (bacteriocins) that inhibit the proliferation of others bacteria. In this process, the microbiota keeps stable, metabolizing subtracts and nondigestible products [1]. Fermentation of nondigestible carbohydrate produces shortchain fatty acids (SCFAs: acetate, propionate, and butyrate), which play an important role in the modulating of different processes in the gastrointestinal tract, including electrolyte, ( $\mathrm{Ca}, \mathrm{Mg}$, and $\mathrm{Fe}$ ) and water absorption, cell proliferation and differentiation, hormones secretion, and activation of immune system $[8,13]$. Furthermore, the SCFAs are used as energy sources by organism, including colonocytes and a small portion liver and muscle [13]. Metabolic functions are also attributed to microbiota, as vitamin production (K, B12, biotin, folic acid, and pantothenic) and aminoacids synthesis from ammoniac or urea [14].

Currently, it is clear that induction and regulation of the immune system depends on the microbiota. Studies suggest that ability of leukocytes to migrate to the focus of inflammation and to destroy microbial pathogens also could be affected by the SCFAs. According to Vinolo et al. [15] short-chain fatty acids could regulate leukocyte function through cytokines (TNF- $\alpha$, IL-2, IL-6, and IL-10), eicosanoids and chemokines production.

From a broader context, enterocytes play an important role in the logistics of the immune system, since his position in contact with the intestinal lumen is crucial for the initial recognition of foreign molecules and to generate signals that are transmitted to the immunocompetent cells. The participation of enterocytes in the defense mechanism is not limited only to innate defense. They may act as antigen presenting cells, inducing an acquired immune response mediated by $\mathrm{T}$ lymphocytes $[16,17]$. Once activated by antigen presenting cells, the expansion of clonal $\mathrm{T}$ cell results in helper lymphocytes (Th-cells) of different phenotypes: Th1, Th2, or regulatory $\mathrm{T}$ cells. The regulatory $\mathrm{T}$ cells play a key role in immune tolerance because they secrete regulatory cytokines, anti-inflammatory tips as IL-10 and TGF- $\beta$, in response to antigens that are recognized as nonpathogens. This mechanism explains how the immunotolerance behaves when exposed to an innocuous antigenic load, such as foods. On the other hand, defects in the activity of these cells favor the development of diseases due to immune dysregulation [17].
In this paper were prioritized the main intra- and extraintestinal pediatric diseases which have relation with the gastrointestinal microbiota. Among gastrointestinal diseases were included Helicobacter pylori infection, necrotizing enterocolitis, inflammatory bowel diseases, celiac disease, constipation, and diarrhea. Among extraintestinal diseases were included obesity and allergic reactions once they are widely researched and discussed nowadays.

\section{Gastrointestinal Microbiota and Diseases}

2.1. Helicobacter pylori Infection. Although the bacterial load in the stomach is low, particular attention has been given to Helicobacter species due to their association with various gastric diseases [1]. Helicobacter pylori is a gramnegative spiral bacteria that causes gastritis, gastric, and duodenal ulcers, stomach cancer, and mucosa-associated lymphoid tissue lymphoma [18], representing one of the most common bacterial infections in the world [19]. In pediatric patients, this infection is associated with abdominal pain of childhood, gastroesophageal reflux disease, and growth retardation [19]. In adults, recent studies suggest that it increases the risk of coronary heart disease [20]. Overall, over $50 \%$ of the world's population is infected by Helicobacter pylori, 30\%-40\% in advanced nations and over $80 \%$ in developing countries [21]. Among individuals younger than 20 years old, the prevalence of infection is around $80 \%$ in developing countries, higher than in developed countries. Variation in prevalence is associated with sociodemographic factors, such as low socioeconomic status, low-income family, and poor living conditions [18].

\subsection{Necrotizing Enterocolitis. Necrotizing enterocolitis} (NEC) is the most common gastrointestinal medical emergency that occurs in neonates. It represents a significant clinical problem in infants and affects up to $10 \%$ of infants who weigh less than $1500 \mathrm{~g}$, especially neonates of extremely low birth weight $(<1000 \mathrm{~g})$ with less than 28 weeks of gestation [22]. The prevalence of mortality ranges between $20-30 \%$. The morbidity prevalence is also high, mainly long-term neurodevelopmental impairment in neonates with extremely low birth weight $[22,23]$. Despite of advances in neonatal intensive care, NEC continues to be a potentially disastrous illness in preterm neonates, without significant changes in mortality and long-term morbidity "incidence" [23].

The pathogenesis is poorly known. There are several factors including prematurity, hypoxia, formula feeding, especially excess protein substrate in the intestinal lumen, sepsis, intestinal ischemia, and colonization of the intestine by pathogenic bacteria $[22,23]$. A recently published study [24] reports higher proportion of Proteobacteria in neonates after diagnosis of NEC, corroborating other findings. Interestingly, in this study, performed on nine neonates patients with NEC and nine in the control group, one week before the diagnosis was found lower proportion of these bacteria in NEC patients compared to the control group [24]. The authors commented that preterm infants with no sufficient 
colonization of Proteobacteria during the first week of life, may not be able to modulate an adaptative immunological response to subsequent increase of Proteobacteria [24]. Therefore, the tolerance mechanism immaturity, influenced by microbiota quality and quantity can be associated with this pathology.

2.3. Inflammatory Bowel Diseases. In the inflammatory bowel diseases (Crohn's disease and ulcerative colitis), there is an anomalous action in the immune system against elements of microbiota that takes place in intestinal mucosa and causes intestinal damages [25]. Patients with inflammatory bowel disease, in the presence of commensal bacteria, have an increase of antibodies IgG and T lymphocytes presented on mucosa are hyperactive, suggesting the suppression of local tolerance mechanisms [26]. In fact, there are several factors that influence the activation and remission of inflammatory activity, as the derivation of fecal stream, the use of antibiotics to treat Crohn's disease and broad-spectrum antibiotics in light of the colon-to-ulcerative colitis [27, 28]. Considering that Crohn's disease in humans occurs in the terminal ileum and colon, where the bacterial concentration is higher [26], it is assumed that the intolerance generated by the microbiota, added to genetic predisposition, favors the development of this inflammation [25].

The lamina propria is the tissue site where immune cells initially recognize bacterial antigen, prior to migrating to the distal lymphoid tissue to mount the inflammatory response [29]. Epithelial cells present receptors named Tolllike receptors and NOD2 receptors that are important to start immune response. Once activated, these receptors can generate an intracellular response, producing proinflammatory cytokines [30]. This mechanism favors mucosal dendrite cells maturation that after contact with antigen follows to local lymphoid structures, such as Peyer's patches, and draining mesenteric lymph nodes to initiate or maintain $\mathrm{T}$ - and B-cell immune responses. Dendrite cells initiate immune response, control intestinal inflammation, and maintain the tolerance. In this context, mucosal dendrite cells are assumed to play key roles regulating immune responses in the antigenic gastrointestinal environment, maintaining intestinal homeostasis and allowing the pacific coexistence with the endogenous microflora [29]. In normal subjects, the commensal flora is unable to cross the epithelial barrier; however, when any of these bacteria pass through intestinal barrier, are quickly phagocytosed by macrophages of the mucosa, avoiding the activation of intestinal immune response; but, on the other hand, when pathogens microorganims cross the barrier, this response is activated [31].

Ulcerative colitis and Crohn's diseases are generally developed in areas with the highest concentration of enteric microbiota, suggesting that commensal bacteria associated to a genetic susceptibility can contribute to the pathogenesis of these diseases [32]. Furthermore, several studies cited by Fava and Danese [33] suggest that microbiota found in patients with inflammatory bowel disease is different from healthy individuals, suggesting that dysbiosis may lead to intolerance. These patients present a poorly diversified microbiota, with prevalence of Clostridia, Bactoroides, and Bifidobacteria (commensal microbiota) and a concomitant increase in detrimental bacteria, such as Escherichia coli, uncommon in individuals without inflammatory bowel disorders [33]. The proportion of detrimental bacteria could represent $30-40 \%$ of dominant bacteria, although significant, the relation of cause and effect is not well established [34]. It is interesting to mention that the low diversity of species is related to instability in the ecosystem, which implies a greater predisposition to change the composition by environmental influences. Thus, ecosystem instability may favor the risk of inflammation.

2.4. Celiac Disease. Celiac disease is an autoimmune disease of the small intestine, characterized by life-long intolerance to the gliadin and related prolamins from wheat and other cereals that occurs in genetically predisposed individuals to gluten intolerance [35]. Through intolerance mechanisms to gluten are activated both immune responses: (1) adaptive immune response, dominated by Th1 pro-inflammatory cytokines and (2) innate immune response, mediated by interleukin-15, that result in epithelial alterations, with changes in permeability and integrity of intestinal mucosa, favoring active phase of the disease [36]. In response to immune activation is developed atrophy of intestinal villous with different degrees, until the complete villous atrophy, associated with an increase in crypt length and cells number [35]. This abnormality in the mucosal structure may lead to nutrient malabsorption, failure to thrive, osteopenia, osteoporosis, extraintestinal autoimmune disorders as herpetiform dermatitis, infertility and neoplastic processes, which can be prevented with the exclusion of gluten from the diet. Thus, a strict gluten-free diet is the only therapy for remission of the clinical symptoms and health complications in these patients $[35,37]$.

The role of microbiota in celiac disease is not completely understood in comparison with healthy individuals [38]. Genetic factors were associated with the colonization of Bacteroides species [39]. Studies showed that a strict glutenfree diet, in celiac patients, promotes reduction in beneficial bacterial counts, especially Bifidobacterium and Lactobacillus compared to gram-negative bacteria (Bacteroides and E. coli) [36]. This microbiota alteration due to gluten exclusion may result from the exclusion of important carbohydrates sources, the main energy source for commensal microbiota [39]. The dietetic treatment for these patients does not favor completely the intestinal homeostasis; however, the immune suppressive response by microbiota may be beneficial for celiac disease patients [40].

It is estimated that over 1 in every 100 newborn babies will develop the disease throughout his life. In the past, it was thought that celiac disease rarely appears in childhood, nowadays, is known as a relatively common disease that can be diagnosed at any age. This is because the prevalence of typical forms of the disease are higher in children than in adults, respectively, $67.0 \%$ versus $14.3 \%$ of the cases [41], but up to $20 \%$ of the patients are diagnosed after 60 years old. Currently are observed great advances in the celiac disease diagnosis that will benefit patients and their families, as also asymptomatic individuals [37]. Parallel to this, advances 
in knowledge of the microbiota may benefit the disease prevention.

2.5. Constipation. Chronic constipation is the main complaint on pediatrics consults reaching $25 \%$ of gastroenterology services $[42,43]$. It is a common condition in pediatric patients with multifactorial etiology, being 90 95\% due to functional causes [44]. Rome III criteria define chronic constipation as the presence of at least two of the following symptoms for two or more months: (1) two or fewer defecations per week; (2) at least one episode of fecal incontinence per week; (3) history of retentive posturing or excessive volitional stool retention; (4) history of painful or hard bowel movements; (5) presence of a large fecal mass in the rectum; (6) history of wide diameter stools that may obstruct the toilet [43].

Zoppi et al. [45] with the aim of investigating the composition of the intestinal ecosystem in chronic functional constipation found dysbiosis in constipated children (mean of age $8.6 \pm 2.9$ years). In this study was observed a higher number of Clostridia and Bifidobacteria in feces than in healthy children. Evaluating infants, Aguirre et al. [46] found that artificial feeding increases by 4.5 times the risk of constipation in relation to predominant breastfeeding. In breastfed infants, Bifidobacterium spp. predominate, representing up to $90 \%$ of the total fecal microbiota, whereas in formulafed infants the microbiota is more heterogeneous $[47,48]$. Breast-milk has been shown to be a continuous source of commensal bacteria to the infant gut, maybe because the prebiotics composition that stimulates growth and maintenance of Lactobacillus and Bifidobacterium [47, 48]. The addition of prebiotics to artificial infant formula increases the bifidobacteria counting [49], the stool frequency and decreases stool consistency, similar characteristics than found in breast-fed infants [50, 51].

The presence of commensal bacteria in the colon promotes the reduction of $\mathrm{pH}$ which stimulates further growth, due to its high percentage of water, that provides more humid stool $[52,53]$ and lower consistency, which facilitate their excretion [54].

2.6. Diarrhea. Diarrhea is a symptom defined as the loose of watery unformed stools for more than three times in one day or defecation volume greater than $200 \mathrm{~mL} /$ day. The acute diarrhea is the main symptom of acute gastroenteritis. According to ESPGHAN (European Society for Paediatric Gastroenterology, Hepatology, and Nutrition), acute gastroenteritis is defined as the decrease in the feces consistency (soft or liquid) and/or an increase of stool frequency (3 or more times in 24 hours) with or without fever or vomiting, usually lasting less than 7 days and never exceeding 14 days [55]. In some cases, it is accompanied by abdominal pain and dehydration [56].

In Europe, the incidence of diarrhea varies between 0.5 and 1.9 episodes per year among children under 3 years old [55]. A recent systematic review, including 139 low- and middle-income countries, estimated that the incidence of diarrhea declined from 3.4 episodes/child per year in 1990 to 2.9 episodes/child per year in 2010, being highest among infants 6-11 month of age (4.5 episodes/child per year in 2010) [57]. Although there was a reduction on the incidence of episodes per child over the years, the number of episodes is still high, nearly 1.7 billion reported in 2010 [57].

The most common etiologic agents are Rotaviruses and, among bacteria, Campylobacter is the most common, followed by Salmonella. Parasites such as Giardia lamblia and Cryptosporidium are an infrequent cause of diarrhea in healthy children. The main etiologic agents can change with the child age: in children under 1 year, Rotavirus, Norovirus, Adenovirus, and Salmonella prevail. From 1 to 4 years old the same agents prevails, adding Campylobacter and Yersinia. In children older than 5 years, Campylobacter, Salmonella, and Rotavirus [55]. Diarrhea associated with antibiotics administration is also a frequent, reaching an incidence up to $30 \%$ [58].

The main pathogenic mechanism of gastroenteritis, regardless if its cause, is changes in the absorption and secretion of water and electrolytes through the intestinal mucosa, it increases, especially in infants, the risk of developing acute dehydration, considered the main complication of gastroenteritis [59]. In this sense, a modulation of the intestinal microbiota can help to control symptoms and complications of diarrhea as part of an adjuvant treatment.

\section{Intestinal Microbiota and Extraintestinal Diseases}

The intestine is the first barrier for nutrients and luminal components, constituting one of the first lines of defense against infectious agents and allergens [26]. Bacterial translocation is caused by increases intestinal permeability as a result of a disrupter's intestinal barrier [60]. As previously mentioned, alterations of intestinal microbiota can be related to the development of extraintestinal diseases as obesity and allergy reactions.

3.1. Obesity. Nowadays, obesity is becoming a serious public health problem. The prevalence of childhood obesity can reach $20 \%$ in European Union countries, and is increasing in developing countries [61]. The impaired balance between energy intake and energy expenditure is the main risk factor to excessive weight gain in children and adolescents.

Recent studies suggest differences in the quantity and quality of microbiota in obese and lean children as mentioned by Angelakis et al. [62]. In a prospective followup, Kalliomäki et al. [63] observed that children with normal weight at 7 years presented higher prevalence of Bifidobacterium species during the first year of life than those with overweight. The presence of bacteria in the newborn is influenced by maternal bacteria and subsequently by exposure to breast milk or type of feeding adopted [62].

Before pregnancy, overweight women have a higher number of Bacteroides than women with normal weight. In addition, an increase in Bacteroides number during pregnancy is associated with excessive weight gain [64]. In relation to the reduction or increase in the number of Bacteroides in obese and not obese adults, studies are 
controversial, but many of them, conclude that Bacteroides increases in obese, including individuals with diabetes [62]. In an experimental animal model, an increase of Bacteroides in the gut microbiota was associated to predisposition toward energy storage and obesity [63]. In adults, a recent metaanalysis, did not find any difference in the Bacteroides concentration between obese and normal-weight individuals [62].

Among children, a high intestinal Bacteroides fragilis and low Staphylococcus concentration, when infants, were associated with higher BMI in preschool children [65]. On the other hand, children with excessive weight at 7 years old did not present significant increase in the number of Bacteroides when compared to normal-weight children at the same age [63]. In adolescents and adults, a significant increase in the ratio of Bacteroides was correlated to weight loss, after the weight lost program [62].

Until this moment, the main association of intestinal microbiota with obesity is related to Bifidobacteria presence. A meta-analysis performed with 159 obese versus 189 control subjects, from six published studies, demonstrated a significant Bifidobacteria depletion in obese group [62]. Other meta-analysis showed that microbiota of obese individuals presents lesser Firmicutes and Methanobrevibacter spp. concentration than normal weight individuals [62]. Thus, the studies suggest a causal relation between microbiota and obesity.

3.2. Allergic Reactions. In occidental countries, the prevalence of alimentary allergy can affect $6-8 \%$ of children lower than 10 years old and $1-4 \%$ of adult population. The alimentary allergic manifestation can occur anywhere in the body, including gastrointestinal tract, skin, and respiratory system [66]. Several studies show an increased intestinal permeability in patients with allergies, which facilitates the passage of proteic antigens coming from diet [67]. In addition, epidemiological studies demonstrated that allergic children have a different microbiota from healthy children with higher levels of Clostridia and lower levels of Bifidobacteria [68]. On the other hand, in nonallergic children, in the composition of the microbiota are found more commonly Bifidobacteria and Lactobacilli, suggesting that modulation of the microbiota can help to promote prevention of allergic manifestation $[68,69]$.

Most of publishes about modulation of intestinal microbiota in allergic patients are focused on dermatological pathology, especially in atopic dermatitis. It is a chronic disorder in the skin that can affect from $10 \%$ to $25 \%$ of occidental children [70]. Genetics is not the only risk factor, the "hygiene hypothesis" proposes that a quick increase in atopic manifestations may be due to less exposure to infections in the first stage of life. Following this theory, a relative lack of microbial stimulation of the infantile gut immune system and the exaggerated hygiene from the typical western lifestyle during early childhood, influencing the immune maturation [68].

Development of the child's immune system tends to be directed towards a T helper type 2 (Th2) phenotype in infants, whereas postnatal maturation is associated with gradual inhibition of Th2 and increasing Th1 affinity. According to Prescott et al. [71], nonatopic children during the first year of life present rapid suppression of Th2 responses, while the response in atopic children is stimulated. The predominant Th2 response is associated with increased production of IgE antibodies against environmental antigens and eosinophilia, forming the basis of allergic processes.

Considering microbiota and atopic reactions, other studies also showed that early colonization with potentially more pathogenic bacteria such as Clostridium difficile and Staphylococcus aureus is more likely to occur in children who go on to develop allergy [68].

\section{Modulation of Intestinal Microbiota}

Scientific advances leads every day to more knowledge on the microbiota and its association with pediatric diseases. In the face of published studies is seeking alternatives for modulation of intestinal microbiota, in order to prevent and treat a wide range of diseases. At present, the probiotic use is being considered a therapeutic strategy due to its ability to inhibit pathogenic bacteria overgrowth and the development of inflammatory intestinal infections [72]. Probiotics are defined as "live microorganisms that when administered in adequate amounts confer a health benefit to the host" [8]. For a microorganism strain to be considered beneficial to organism or probiotic needs to fulfill the following criteria: (1) remains viable at the intestine, resisting gastric acid digestion and bile salts; (2) adheres to the gastrointestinal epithelium; (3) be metabolically active; (4) decreases colon $\mathrm{pH}$; (5) shows antibacterial activity against pathogenic bacteria [72]. Lactobacillus plantarum, L. rhamnosus, L. reuteri, L. casei, L. acidophilus, Bifidobacterium longum, B. brevis, and B. bifidum are the main strain with proven probiotic effects. The benefits of a probiotic action vary according to interval time that the bacteria remain in the intestine and their quantity [73].

Although the amount and time of administration are important for the beneficial effects, its recommendation requires attention. The most important concern about probiotic use is the risk of sepsis [72]. Probiotics have specific actions to specific patients. So, it is important to emphasize that probiotics are highly heterogeneous with differences in composition and biological activity [73].

In the following are addressed the indications of probiotic to intestinal microbiota modulation for each disease presented in this paper.

4.1. Helicobacter pylori. Studies in vitro showed that $L$. acidophilus LB associated with antibiotics therapies exerts an agonist effect against the bacteria, affecting negatively growth of bacteria, inhibiting adhesion receptor glycolipids, and decreasing the activity of the urease, essential for their survival in acid environment [74]. In humans, the probiotic strain can improve infection condition, but not enough to $H$. pylori eradication, as demonstrated in a recent published review about Helicobacter pylori infection and childhood [19]. The authors state that the environment where children live is important to prevent this infection. 
The use of supplementation with fermented milk, containing probiotic L. casei DN-114001 (Actimel) for 14 days, benefited the $H$. pylori eradication in children treated with omeprazole, amoxicillin, and clarithromycin during 7 days [75]. This result suggests that the probiotic could be used as adjuvant treatment for eradication of HP in children.

4.2. Necrotizing Enterocolitis. The evaluation of the probiotics use to reduce the risk of NEC are based in two recent meta-analyses. In the first meta-analysis mentioned was selected 11 trials using a fixed-effect model, with preterm very low-body-weight neonates $(<34$ weeks of gestation and birth weight $<1500 \mathrm{~g}$ ). An enteral administration of any probiotic commenced within the first 10 days of life and continued for at least 7 days, allowed 30\% reduction in the incidence of NEC. In addition was demonstrated in supplemented preterm neonate a lower risk of death [23]. In the second meta-analysis, enteral probiotics supplementation also reduced the incidence of severe NEC (RR 0.32; 95\% IC 0.17-0.6) and mortality (RR 0.43; 95\% IC 0.25-0.75), in preterm neonates ( $<37$ weeks of gestation and/or $<2,500 \mathrm{~g}$ birth weight) [76]. In both studies, the use of probiotics does not decrease the risk of sepsis.

The studies found significant variation in probiotics strains and protocols treatment, data suggest that additional placebo-controlled trials are necessary. According to Deshpande et al. [23] if offered as a routine therapy for preterm neonates a strict product selection should be made, including a close monitoring of the target population before the consumption. Although the results are positive, the ESPGHAN Committee on Nutrition still does not recommend the routine use of probiotics in order to prevent NEC [77].

4.3. Inflammatory Bowel Diseases. Probiotics can adjust the metabolic activity of the intestinal flora and their components by preventing bacterial overgrowth, maintaining the integrity of the intestinal mucosal barrier, improving their function, permeability, stability, and induction of T-cell apoptosis. Through this action mechanism, the probiotics can regulate the immune response and reduce the secretion of pro-inflammatory factors $[4,8]$.

In ulcerative colitis treatment, the use of Escherichia coli Nissle, 1917, nonpathogenic, was evaluated 116 patients aged 18-80 years old in a randomized clinical trial controlled with mesalazine. The authors found a $74.6 \%$ reduction of remission in patients that consumed mesalazine versus $68.4 \%$ in patient with probiotic consumption (OR $1.35 ; 95 \%$ IC 0.6-3.04). In this study, the time to remission was similar, respectively, 44 and 42 days [78]. On the other hand, a metaanalysis published in 2010, selecting 13 randomized controlled studies, suggests that the probiotic use did not provide additional benefit in an induction remission, although in the remission maintenance of symptoms, the probiotic 1.36 (95\% CI 1.07-1.73) was more effective than placebo 0.69 (95\% CI 2.47-1.01) [79]. Considering controlled studies, Escherichi coli, Nissle, $1917\left(2.5 \times 10^{10}\right)[78,80]$, Bifidobacteria (bifidobacteria-fermented milk $100 \mathrm{~mL} /$ day) [81], and
Lactobacilli GG $\left(18 \times 10^{9}\right)[82]$ were probiotics that resemble mesalazine effect in the maintenance treatment of remission.

In the treatment of active and inactive Crohn's diseases, many studies with several probiotics strain (E. coli Nissle, LGG, L. johnsonii LA1, S. boulardii y VSL number 3) were performed, but the sample size was small. Furthermore, these studies, as well as in experimental animal studies [83], the results showed no significant difference in the reduction of inflammation [84]. In the open label pilot evaluation using Lactobacillus GG $\left(10^{10} \mathrm{CFU}\right)$ twice a day for 6 months, 3 of 4 children were reported to have improved Pediatric Crohn's Disease Index (PCDAI) scores. But more randomized controlled trials are required to assess the efficacy of Lactobacillus GG in children Crohn's disease as well as evaluate other probiotics strains [85].

4.4. Celiac Disease. Currently, there is no probiotic indication as adjuvant treatment for celiac diseases. However, the advancement of microbiota knowledge will allow future investigations, especially about microbiology and genetic predisposition.

The major genetic risk factor on celiac disease is represented by human leukocyte antigen (HLA)-DQ genes [35]. The relation between milk-feeding type and HLA-genotype on intestinal microbiota composition of infants with a family history of celiac disease was recently studied. Palma et al. [6] published the first study that found this association. According to the authors, infants with high genetic risk of developing celiac disease presented a higher number of B. fragilis and Staphylococcus spp., and lower number of Bifidobacterium spp. and B. longum. Breast-feeding reduced the genotype-related differences in microbiota composition, which could partly explain the protective role attributed to breast milk in this disorder. Epidemiological studies suggest that breast-feeding confers a protective effect against the risk of celiac disease development, mainly when gluten is introduced in the diet while the infants are still breastfed [86]. Therefore, the protective effect of breast-feeding is also related to its ability to modulate the intestinal microbiota in infants, favoring the increase and maintenance of Bifidobacteria.

4.5. Constipation. A recent systematic review concerning nonpharmacological treatments for childhood constipation considers poor the evidence about probiotics effects [87]. A review on adults and children indicates that the use of probiotics for the constipation treatment should be considered investigational [88]. In adults, studies demonstrate beneficial probiotic effect compared to placebo, as can be seen in a crossover study with Lactobacillus casei Shirota $\left(0.5-5 \times 10^{9} \mathrm{UCF}\right)[89]$ and in a randomized control trial with $E$. coli Nissle, $1917\left(6.5 \times 10^{9} \mathrm{UCF}\right)$ [90]. In pediatric patients, the positive probiotic effect in functional constipation was observed with different probiotic strains. The yogurt supplemented with $10^{9} \mathrm{CFU} / \mathrm{mL}$ Bifidobacterium longum compared with placebo presented significant differences for defecation frequency, defecation pain, and abdominal pain in a crossover, double-blind controlled trial that included 
59 children and adolescents aged 5-15 years old [91]. The treatment with Lactobacillus casei rhamnosus Lcr35 $(8 \times$ $10^{8} \mathrm{CFU} /$ day) presented no difference in efficacy compared with magnesium oxide ( $50 \mathrm{mg} / \mathrm{kg} / \mathrm{day})$, being the occurrence of abdominal pain less prevalent in the Lcr35 group [92]. In a pilot study to evaluate efficacy of a probiotic mixture (Ecologic Relief: Bifidobacteria B. bifidum, B. infantis, B. longum, Lactobacilli casei, L. plantarum and L. rhamnosus) in pediatric patients aged $4-16$ years during 4 weeks, it was observed a significant effect of this mixture $\left(4 \times 10^{9} \mathrm{CFU}\right)$, increasing stool frequency and decreasing the number of fecal incontinence and abdominal pain [93]. On the other hand, the Lactobacillus GG as an adjunct to lactulose for the treatment of functional constipation in children presented no positive effect [94], but in this case, the laxative effect of lactulose should be considered. In general, the probiotic use seems to benefit the functional constipation in pediatric patients, but a larger number of cases and a longer followup are required to establish a conclusion.

In normal healthy infants (under 6 months of life), a randomized controlled trial demonstrated a significant increase in stool frequency and fecal consistency improvement using a LGG-supplemented formula [95]. Contradictory, the administration of B. lactis, B. longum BL 999, and rhamnosus LPR was not associated with change in stool frequency and stool consistency, resulting unclear the probiotic effect in infants according to ESPGHAN commentary published in 2012 [77].

4.6. Diarrhea. The probiotics use can benefit the reduction of diarrheal symptoms through multiple action mechanisms. Firstly, it can preserve the function of the intestinal epithelium, avoiding the increased intestinal permeability [96] and the invasion of pathogenic microorganisms [97]. Secondly, through colon acidification, bactericides production, competition for nutrients, and IgA production, it prevents the growth of pathogenic strains [98]. Finally, the production of short chain fatty acids in the colon stimulates the absorption of sodium by the colonocytes [8]. Lactobacillus strains and Saccharomyces boulardii, a type of yeast, are the most studied microorganisms.

Several meta-analyses $[58,99-102]$ confirmed the beneficial effects of Lactobacillus GG and Saccharomyces boulardii in adjuvant treatment of diarrhea. Although the randomized clinical trials realized with Saccharomyces boulardii presented a high methodological variability, they show positive results. In a large meta-analysis, it was verified that this yeast reduced the risk of diarrhea at 3 days (RR 0.66 ; 95\% IC 0.55-0.77), and on average reduction of $30.48 \mathrm{~h}$ (95\% IC 18.51-42.46 h), proving its effective action on rehydration treatment [103].

In antibiotic therapy, the auxiliary supplementation of Saccharomyces boulardii decreased the risk of diarrhea from $17.2 \%$ to $6.7 \%$ (RR 0.43 ; 95\% IC $0.23-0.78$ ) in children and adolescents between 6 month and 14 years old [58]. In another revision including pediatric patients (1015 subjects treat and 971 control), the authors observed a significant reduction in the incidence of antibiotic-associated diarrhea with probiotic administration (RR 0.49 ; 95\% IC 0.32-0.74) [104]. In a more recent study, including 3432 children and adolescents between $0-18$ years of age, positive results were observed to probiotics, but in a subgroup analysis was indicated that higher doses ( $\geq 5$ billion CFU/day) are more effective than lower probiotic doses $(<5$ billion CFU/day) $(P=0.010)$ [105]. According to Johnston et al. [105], the incidence of antibiotic-associated diarrhea for high-dose studies in the probiotic and placebo groups was, respectively, $8 \%$ and $22 \%$ (1474 participants; RR 0.40; 95\% CI 0.29-0.55). While for low-dose studies was found an incidence of $8 \%$ in the probiotic group and $11 \%$ in the control group (1382 participants; RR 0.80; 95\% CI 0.53-1.21) [105].

In children with acute diarrhea, the Lactobacillus GG supplementation is linked to a significant decrease of diarrhea duration, especially caused by rotavirus and diarrhea with lower seven-day risk. Although no percussion in feces volume was observed, its administration was associated with a moderate benefit [100].

In hospitalized children, the consumption of Lactobacillus GG compared with placebo has the potential effect to reduce the overall incidence of healthcare-associated diarrhoea (RR 0.37; 95\% CI 0.23-0.59), including symptomatic rotavirus gastroenteritis (RR 0.49 ; 95\% CI $0.28-$ 0.86) [102]. The Saccharomyces boulardii reduced the duration of diarrhea in hospitalized patients with acute infectious diarrhea [106]. Dinleyici et al. [106] found a reduction of approximately $24 \mathrm{~h}$ in diarrhea duration and a $20 \mathrm{~h}$ reduction in hospitalization, a significant impact on clinical practice.

There is a strong evidence of the clinical benefit of Lactobacillus and Saccharomyces boulardii [107] to diarrhea treatment. About the efficacy and safety of other probiotics agents on pediatric diarrhea treatment, it is premature to draw conclusions. Further studies to evaluate the dose effects and its safety are demanded [105].

4.7. Obesity. For obesity, no auxiliary treatment with probiotics is recommended. Previously several short-term randomized controlled trials showed the benefit of probiotics to insulin sensitivity, inflammatory markers and glucose tolerance [108]. Considering that Bifidobacteria depletion during lactation is an associated factor to obesity development in school age [63], and the first years of life have a crucial impact on the individual's gut microbiota composition, studies have been developed to evaluate the probiotic supplement during prenatal and postnatal periods [108].

The impact of perinatal probiotic intervention on the development of overweight during a 10-year followup was evaluated by Luoto et al. [109]. In this study, the consumption of $10^{10} \mathrm{CFU}$ of Lactobacillus GG 4 weeks before expected delivery extended for 6 months postnatally appeared to moderate the excessive weight gain especially among children until 24-48 months. Lactobacillus GG and Bifidobacterium lactis administrated during pregnancy reduced the risk of gestational diabetes mellitus and decreased the risk of larger birth size in affected cases [110]. Currently, the findings in pediatric subjects are limited. Although studies demonstrated an association between obesity and type 2 diabetes with specific changes in intestinal microbiota composition, mainly in animal model [111], further studies to human extrapolation are necessary. 
4.8. Allergic Reaction. There are many studies that investigated the role of probiotics in atopic dermatitis in children younger than 2 years old. The offering of Lactobacillus GG compared with placebo reduced by half the risk of atopic eczema in children genetically susceptible in the first year of life (RR 0.51; 95\% CI 0.32-0.84) [112]. In this study, both administration forms were effective: by infant, during 6 months postnatal or by his mothers, during pregnancy. Other studies demonstrated a significant reduction of severity scoring of atopic dermatitis index using Lactobacillus fermentum VRI-033 PCC $1 \times 10^{9} \mathrm{CFU}$ twice a day during 8 weeks [113] and Lactobacillus GG in infants suspected cow's milk allergy IgE-sensitized [114]. In children older than 2 years was also found significant difference on decreasing of severity scoring of atopic dermatitis index with Lactobacillus GG [115] and Lactobacillus reuteri [116] supplementation when compared to placebo.

A meta-analysis published in 2012 based on 14 studies provided evidence to support a moderate role of probiotics use in atopic dermatitis. Probiotic supplementation decreased the incidence of atopic dermatitis (RR 0.79; 95\% CI $0.71-0.88$ ) and IgE-mediated atopic dermatitis in infants (RR 0.80; 95\% CI 0.66-0.96), when used during pregnancy or early life [117]. Furthermore, it is important to comment that breast-feeding may protect against infection and atopy in infants, delivering IgA and other protective molecules TGF and IL-10 (with anti-inflammatory properties) and favoring Lactobacilli and Bifidobacteria increase [66].

Considering respiratory symptoms, the Bifidobacterium lactis is the most common probiotic studied in children. Used in infant born at term which mother diagnosed with HIV, the B. lactis CNCM I-3446 demonstrated no significant effect in the rate of bronchopneumonia (RR 0.75; 95\% CI: $0.2-$ 2.6) [118]. When tested in infants from 4 to 10 month of age, $B$. lactis, as $L$. reuteri also did not present effect on the rate and duration of respiratory illness. In this study was observed that infants fed with formula control had more diarrhea episodes and episodes of longer duration [119].

The infants formula supplemented with Lactobacillus salivarius CECT5713 $\left(2 \times 10^{6} \mathrm{CFU}\right)$ provided a significant reduction in the number of episodes of respiratory infections compared with control formula, respectively, 53 versus 36 after 6 months of consumption [120]. The use of L. johnsonii La1-supplemented formula did not show any positive effect on the number of respiratory infections compared to the control formula [121]. According to ESPGHAN Committee on Nutrition, available data are insufficient to draw a reliable conclusion about using probiotic supplement formula on prevention of respiratory infections in infants [77].

\section{Conclusion}

The key role in human health could depend on homeostasis balance among microbial species populating the gut. Therefore, the intestinal microbiota is considered not only a potential biomarker, but also an important factor in the adjuvant therapeutic a therapeutic target in intra- and extra-intestinal diseases. Although all people are genetically programmed, these changes in gastrointestinal microbiota can be modulated. Nevertheless, the type of bacteria, dosing regimen, delivery method, and the host should be considered when indicated a probiotic supplementation.

\section{Conflict of Interests}

The authors have declared that they have no conflict of interests.

\section{References}

[1] M. Roberfroid, G. R. Gibson, L. Hoyles et al., "Prebiotic effects: metabolic and health benefits," British Journal of Nutrition, vol. 104, supplement 2, pp. S1-S63, 2010.

[2] E. Bezirtzoglou and C. Romond, "Effect of the feeding practices on the establishment of bacterial interactions in the intestine of the newborn delivered by cesarian section," Journal of Perinatal Medicine, vol. 18, no. 2, pp. 139-143, 1990.

[3] I. Le Huërou-Luron, S. Blat, and G. Boudry, "Breast- v. formula-feeding: impacts on the digestive tract and immediate and long-term health effects," Nutrition Research Reviews, vol. 23, no. 1, pp. 23-36, 2010.

[4] S. Salminen and E. Isolauri, "Intestinal colonization, microbiota, and probiotics," Journal of Pediatrics, vol. 149, no. 3, pp. S115-S120, 2006.

[5] J. A. Stewart, V. S. Chadwick, and A. Murray, "Investigations into the influence of host genetics on the predominant eubacteria in the faecal microflora of children," Journal of Medical Microbiology, vol. 54, no. 12, pp. 1239-1242, 2005.

[6] G. D. Palma, A. Capilla, E. Nova et al., "Influence of milkfeeding type and genetic risk of developing coeliac disease on intestinal microbiota of infants: the PROFICEL study," PLoS One, vol. 7, no. 2, Article ID e30791, 2012.

[7] S. M. Collins, "Translating symptoms into mechanisms: functional GI disorders," Advances in Physiology Education, vol. 31, no. 4, pp. 329-331, 2007.

[8] M. B. Morais and C. M. Jacob, "The role of probiotics and prebiotics in pediatric practice," Jornal de Pediatria, vol. 82, supplement 5, pp. S189-S197, 2006.

[9] G. Reuter, "The Lactobacillus and Bifidobacterium microflora of the human intestine: composition and succession," Current Issues in Intestinal Microbiology, vol. 2, no. 2, pp. 43-53, 2001.

[10] E. Decker, M. Hornef, and S. Stockinger, "Cesarean delivery is associated with celiac disease but not inflammatory bowel disease in children," Gut Microbes, vol. 2, no. 2, pp. 91-98, 2011.

[11] C. Gutiérrez, A. Marco, A. Nogales, and R. Tebar, "Total and segmental colonic transit time and anorectal manometry in children with chronic idiopathic constipation," Journal of Pediatric Gastroenterology and Nutrition, vol. 35, no. 1, pp. 31-38, 2002.

[12] B. R. Southwell, M. C. C. Clarke, J. Sutcliffe, and J. M. Hutson, "Colonic transit studies: normal values for adults and children with comparison of radiological and scintigraphic methods," Pediatric Surgery International, vol. 25, no. 7, pp. 559-572, 2009.

[13] J. L. Rombeau and S. A. Kripke, "Metabolic and intestinal effects of short-chain fatty acids," Journal of Parenteral and Enteral Nutrition, vol. 14, supplement 5, pp. 181S-185S, 1990. 
[14] L. V. Hooper, T. Midtvedt, and J. I. Gordon, "How hostmicrobial interactions shape the nutrient environment of the mammalian intestine," Annual Review of Nutrition, vol. 22, pp. 283-307, 2002.

[15] M. A. R. Vinolo, H. G. Rodrigues, R. T. Nachbar, and R. Curi, "Regulation of inflammation by short chain fatty acids," Nutrients, vol. 3, no. 10, pp. 858-876, 2011.

[16] J. H. Cummings, J. M. Antoine, F. Azpiroz et al., "PASSCLAIM - gut health and immunity," European Journal of Nutrition, vol. 43, supplement 2, pp. II118-II173, 2004.

[17] G. A. W. Rook and L. R. Brunet, "Microbes, immunoregulation, and the gut," Gut, vol. 54, no. 3, pp. 317-320, 2005.

[18] M. Oleastro, A. Pelerito, P. Nogueira et al., "Prevalence and incidence of Helicobacter pylori infection in a healthy pediatric population in the lisbon area," Helicobacter, vol. 16, no. 5, pp. 363-372, 2011.

[19] P. Mourad-Baars, S. Hussey, and N. L. Jones, "Helicobacter pylori infection and childhood," Helicobacter, vol. 15, supplement 1, pp. 53-59, 2010.

[20] V. Pasceri, G. Patti, G. Cammarota, C. Pristipino, G. Richichi, and G. Di Sciascio, "Virulent strains of Helicobacter pylori and vascular diseases: a meta-analysis," American Heart Journal, vol. 151, no. 6, pp. 1215-1222, 2006.

[21] C. W. Park, J. H. Chung, H. J. Min et al., "Helicobacter pylori in middle ear of children with otitis media with effusion," Chinese Medical Journal, vol. 124, no. 24, pp. 4275-4278, 2011.

[22] W. A. Mihatsch, C. P. Braegger, T. Decsi et al., "Critical systematic review of the level of evidence for routine use of probiotics for reduction of mortality and prevention of necrotizing enterocolitis and sepsis in preterm infants," Clinical Nutrition, vol. 31, no. 1, pp. 6-15, 2012.

[23] G. Deshpande, S. Rao, S. Patole, and M. Bulsara, "Updated meta-analysis of probiotics for preventing necrotizing enterocolitis in preterm neonates," Pediatrics, vol. 125, no. 5, pp. 921-930, 2010.

[24] V. Mai, C. M. Young, M. Ukhanova et al., "Fecal microbiota in premature infants prior to necrotizing enterocolitis," PLoS ONE, vol. 6, no. 6, Article ID e20647, 2011.

[25] F. Shanahan, "Inflammatory bowel disease: immunodiagnostics, immunotherapeutics, and ecotherapeutics," Gastroenterology, vol. 120, no. 3, pp. 622-635, 2001.

[26] B. L. Kelsall, "Innate and adaptive mechanisms to control of pathological intestinal inflammation," Journal of Pathology, vol. 214, no. 2, pp. 242-259, 2008.

[27] G. R. D’Haens, K. Geboes, M. Peeters, F. Baert, F. Penninckx, and P. Rutgeerts, "Early lesions of recurrent Crohn's disease caused by infusion of intestinal contents in excluded ileum," Gastroenterology, vol. 114, no. 2, pp. 262-267, 1998.

[28] R. B. Sartor, "Therapeutic manipulation of the enteric microflora in inflammatory bowel diseases: antibiotics, probiotics, and prebiotics," Gastroenterology, vol. 126, no. 6, pp. 1620-1633, 2004.

[29] J. H. Niess, "Role of mucosal dendritic cells in inflammatory bowel disease," World Journal of Gastroenterology, vol. 14, no. 33, pp. 5138-5148, 2008.

[30] P. J. Sansonetti, "War and peace at mucosal surfaces," Nature Reviews Immunology, vol. 4, no. 12, pp. 953-964, 2004.

[31] A. J. Macpherson, D. Gatto, E. Sainsbury, G. R. Harriman, H. Hengartner, and R. M. Zinkernagel, "A primitive T cellindependent mechanism of intestinal mucosal IgA responses to commensal bacteria," Science, vol. 288, no. 5474, pp. 2222 2226, 2000.
[32] R. B. Sartor, "Microbial influences in inflammatory bowel diseases," Gastroenterology, vol. 134, no. 2, pp. 577-594, 2008.

[33] F. Fava and S. Danese, "Intestinal microbiota in inflammatory bowel disease: friend of foe?" World Journal of Gastroenterology, vol. 17, no. 5, pp. 557-566, 2011.

[34] M. Llopis, M. Antolín, F. Guarner, A. Salas, and J. R. Malagelada, "Mucosal colonisation with Lactobacillus casei mitigates barrier injury induced by exposure to trinitronbenzene sulphonic acid," Gut, vol. 54, no. 7, pp. 955-959, 2005.

[35] I. Polanco, "Celiac disease," Journal of Pediatric Gastroenterology and Nutrition, vol. 47, supplement 1, pp. S3-S6, 2008.

[36] I. Nadal, E. Donant, C. Ribes-Koninckx, M. Calabuig, and Y. Sanz, "Imbalance in the composition of the duodenal microbiota of children with coeliac disease," Journal of Medical Microbiology, vol. 56, pp. 1669-1674, 2007.

[37] S. Husby, S. Koletzko, I. R. Korponay-Szabó et al., "European Society for Pediatric Gastroenterology, Hepatology, and Nutrition guidelines for the diagnosis of coeliac disease," Journal of Pediatric Gastroenterology and Nutrition, vol. 54, no. 1, pp. 136-160, 2012.

[38] J. Kopecný, J. Mrázek, K. Fliegerová, P. Frühauf, and L. Tucková, "The intestinal microflora of childhood patients with indicated celiac disease," Folia Microbiologica, vol. 53, no. 3, pp. 214-216, 2008.

[39] E. Sánchez, G. De Palma, A. Capilla et al., "Influence of environmental and genetic factors linked to celiac disease risk on infant gut colonization by Bacteroides species," Applied and Environmental Microbiology, vol. 77, no. 15, pp. 53165323, 2011.

[40] Y. Sanz, "Effects of a gluten-free diet on gut microbiota and immune function in healthy adult humans," Gut Microbes, vol. 1, no. 3, pp. 135-137, 2010.

[41] M. J. Llorente-Alonso, M. J. Fernández-Aceñero, and M. Sebastián, "Gluten intolerance: sex- and age-related features," Canadian Journal of Gastroenterology, vol. 20, no. 11, pp. 719-722, 2006.

[42] M. B. Morais and H. V. L. Maffei, "Constipation," Journal of Pediatria, vol. 76, supplement 1, pp. S147-S156, 2000.

[43] A. Rasquin, C. Di Lorenzo, D. Forbes et al., "Childhood functional gastrointestinal disorders: child/adolescent," Gastroenterology, vol. 130, no. 5, pp. 1527-1537, 2006.

[44] M. M. van den Berg, M. A. Benninga, and C. Di Lorenzo, "Epidemiology of childhood constipation: a systematic review," American Journal of Gastroenterology, vol. 101, no. 10, pp. 2401-2409, 2006.

[45] G. Zoppi, M. Cinquetti, A. Luciano, A. Benini, A. Muner, and E. B Minelli, "The intestinal ecosystem in chronic functional constipation," Acta Paediatrica, vol. 87, no. 8, pp. 836-841, 1998.

[46] A. N. Aguirre, M. R. Vitolo, R. F. Puccini, and M. B. De Morais, "Constipation in infants: influence of type of feeding and dietary fiber intake," Jornal de Pediatria, vol. 78, no. 3, pp. 202-208, 2002.

[47] J. Knol, G. M. A. Steenbarkkers, E. G. M. Van der Linde et al., "Bifidobacterial species that are present in breast-fed infants are stimulated in formula fed infants by changing to a formula containing prebiotics," Journal of Pediatric Gastroenterology and Nutrition, vol. 34, article 477, 2002.

[48] J. Knol et al., "An infant formula containing prebiotics changes the intestinal microflora of term infants," Journal of Pediatric Gastroenterology and Nutrition, vol. 36, article 566, 2003. 
[49] F. J. Nóbrega, L. R. Trabulsi, R. Keller et al., "Efeitos do prebiótico (oligossacarídeo) em leite em pó modificado na flora intestinal: comparação com leite em pó modificado sem prebiótico em estudo duplo-cego," Ver Paul Pediatria, vol. 22, no. 4, pp. 205-211, 2004.

[50] N. Moore, C. Chão, L. P. Yang, H. Storm, M. Oliva-Hemker, and J. M. Saavedra, "Effects of fructo-oligosaccharidesupplemented infant cereal: a double-blind, randomized trial," British Journal of Nutrition, vol. 90, no. 3, pp. 581-587, 2003.

[51] G. Boehm, M. Lidestri, P. Casetta et al., "Supplementation of a bovine milk formula with an oligosaccharide mixture increases counts of faecal bifidobacteria in preterm infants," Archives of Disease in Childhood, vol. 86, no. 3, pp. F178F181, 2002.

[52] J. H. Cummings, "Constipation, dietary fibre and the control of large bowel function," Postgraduate Medical Journal, vol. 60, no. 709, pp. 811-819, 1984.

[53] P. J. Aggett, C. Agostoni, I. Axelsson et al., "Nondigestible carbohydrates in the diets of infants and young children: a commentary by the ESPGHAN committee on nutrition," Journal of Pediatric Gastroenterology and Nutrition, vol. 36, no. 3, pp. 329-337, 2003.

[54] C. Cherbut, "Inulin and oligofructose in the dietary fibre concept," British Journal of Nutrition, vol. 87, supplement 2, pp. S159-S162, 2002.

[55] A. Guarino, F. Albano, S. Ashkenazi et al., "European society for paediatric gastroenterology, hepatology, and nutrition/european society for paediatric infectious diseases evidence-based guidelines for the management of acute gastroenteritis in children in europe: executive summary," Journal of Pediatric Gastroenterology and Nutrition, vol. 46, no. 5, pp. 619-621, 2008.

[56] M. M. Cortese and U. D. Parashar, "Prevention of rotavirus gastroenteritis among infants and children recommendations of the advisory committee on immunization practices (ACIP)," Morbidity and Mortality Weekly Report, vol. 58, no. RR-2, pp. 1-25, 2009.

[57] C. L. Fischer Walker, J. Perin, M. J. Aryee, C. Boschi-Pinto, and R. E. Black, "Diarrhea incidence in low- and middleincome countries in 1990 and 2010: a systematic review," BMC Public Health, vol. 12, no. 1, article 220, 2012.

[58] H. Szajewska and J. Mrukowicz, "Meta-analysis: nonpathogenic yeast Saccharomyces boulardii in the prevention of antibiotic-associated diarrhoea," Alimentary Pharmacology and Therapeutics, vol. 22, no. 5, pp. 365-372, 2005.

[59] K. Pringle, S. P. Shah, I. Umulisa et al., "Comparing the accuracy of the three popular clinical dehydration scales in children with diarrhea," International Journal of Emergency Medicine, vol. 47, article 58, 2011.

[60] E. Seki and B. Schnabl, "Role of innate immunity and the microbiota in liver fibrosis: crosstalk between the liver and gut," The Journal of Physiology, vol. 590, pp. 447-458, 2012.

[61] N. Arslan, B. Erdur, and A. Aydin, "Hormones and cytokines in childhood obesity," Indian Pediatrics, vol. 47, no. 10, pp. 829-839, 2010.

[62] E. Angelakis, F. Armougom, M. Million, and D. Raoult, "The relationship between gut microbiota and weight gain in humans," Future Microbiol, vol. 7, no. 1, pp. 91-109, 2012.

[63] M. Kalliomäki, M. C. Collado, S. Salminen, and E. Isolauri, "Early differences in fecal microbiota composition in children may predict overweight," American Journal of Clinical Nutrition, vol. 87, no. 3, pp. 534-538, 2008.
[64] M. C. Collado, E. Isolauri, K. Laitinen, and S. Salminen, "Distinct composition of gut microbiota during pregnancy in overweight and normal-weight women," American Journal of Clinical Nutrition, vol. 88, no. 4, pp. 894-899, 2008.

[65] C. Vael, S. L. Verhulst, V. Nelen, H. Goossens, and K. N. Desager, "Intestinal microflora and body mass index during the first three years of life: an observational study," Gut Pathogens, vol. 3, no. 1, article 8, 2011.

[66] S. Bischoff and S. E. Crowe, "Gastrointestinal food allergy: new insights into pathophysiology and clinical perspectives," Gastroenterology, vol. 128, no. 4, pp. 1089-1113, 2005.

[67] F. Muñoz-López, "Mucosae, allergy and probiotics," Allergologia et Immunopathologia, vol. 32, no. 6, pp. 313-318, 2004.

[68] Ö. Özdemir, "Various effects of different probiotic strains in allergic disorders: an update from laboratory and clinical data," Clinical and Experimental Immunology, vol. 160, no. 3, pp. 295-304, 2010.

[69] K. Laiho, A. Ouwehand, S. Salminen, and E. Isolauri, "Inventing probiotic functional foods for patients with allergic disease," Annals of Allergy, Asthma and Immunology, vol. 89, supplement 1, no. 6, pp. 75-82, 2002.

[70] H. Williams, C. Robertson, A. Stewart et al., "Worldwide variations in the prevalence of symptoms of atopic eczema in the international study of asthma and allergies in childhood," Journal of Allergy and Clinical Immunology, vol. 103, no. 1 I, pp. 125-138, 1999.

[71] S. L. Prescott, C. Macaubas, T. Smallacombe, B. J. Holt, P. D. Sly, and P. G. Holt, "Development of allergen-specific T-cell memory in atopic and normal children," The Lancet, vol. 353, no. 9148, pp. 196-200, 1999.

[72] R. J. Boyle, R. M. Robins-Browne, and M. L. K. Tang, "Probiotic use in clinical practice: what are the risks?" American Journal of Clinical Nutrition, vol. 83, no. 6, pp. 1256-1264, 2006.

[73] NASPGHAN Nutrition Report Committee, S. Michail, F. Sylvester, G. Fuchs, and R. Issenman, "Clinical efficacy of probiotics: review of the evidence with focus on children," Journal of Pediatric Gastroenterology and Nutrition, vol. 43, no. 4, pp. 550-557, 2006.

[74] M. H. Coconnier, V. Lievin, E. Hemery, and A. L. Servin, "Antagonistic activity against Helicobacter infection in vitro and in vivo by the human Lactobacillus acidophilus strain LB," Applied and Environmental Microbiology, vol. 64, no. 11, pp. 4573-4580, 1998.

[75] J. Sýkora, K. Valecková, J. Amlerová et al., "Effects of a specially designed fermented milk product containing probiotic Lactobacillus casei DN-114 001 and the eradication of $H$. pylori in children: a prospective randomized doubleblind study," Journal of Clinical Gastroenterology, vol. 39, no. 8, pp. 692-698, 2005.

[76] K. Alfaleh, J. Anabrees, and D. Bassler, "Probiotics reduce the risk of necrotizing enterocolitis in preterm infants: a metaanalysis," Neonatology, vol. 97, no. 2, pp. 93-99, 2010.

[77] C. Braegger, A. Chmielewska, T. Decsi et al., "Supplementation of infant formula with probiotics and/or prebiotics: a systematic review and comment by the ESPGHAN committee on nutrition," Journal of Pediatric Gastroenterology and Nutrition, vol. 52, no. 2, pp. 238-250, 2011.

[78] B. J. Rembacken, A. M. Snelling, P. M. Hawkey, D. M. Chalmers, and A. T. R. Axon, "Non-pathogenic Escherichia coli versus mesalazine for the treatment of ulcerative colitis: a randomised trial," The Lancet, vol. 354, no. 9179, pp. 635639, 1999. 
[79] L. X. Sang, B. Chang, W. L. Zhang, X. M. Wu, X. H. Li, and M. Jiang, "Remission induction and maintenance effect of probiotics on ulcerative colitis: a meta-analysis," World Journal of Gastroenterology, vol. 16, no. 15, pp. 1908-1915, 2010.

[80] W. Kruis, P. Frič, J. Pokrotnieks et al., "Maintaining remission of ulcerative colitis with the probiotic Escherichia coli Nissle 1917 is as effective as with standard mesalazine," Gut, vol. 53, no. 11, pp. 1617-1623, 2004.

[81] H. Ishikawa, I. Akedo, Y. Umesaki, R. Tanaka, A. Imaoka, and T. Otani, "Randomized controlled trial of the effect of bifidobacteria-fermented milk on ulcerative colitis," Journal of the American College of Nutrition, vol. 22, no. 1, pp. 56-63, 2003.

[82] M. A. Zocco, L. Z. dal Verme, F. Cremonini et al., "Efficacy of Lactobacillus GG in maintaining remission of ulcerative colitis," Alimentary Pharmacology and Therapeutics, vol. 23, no. 11, pp. 1567-1574, 2006.

[83] N. N. Grijó, R. C. Borra, and V. L. Sdepanian, "Proinflammatory and anti-inflammatory cytokines present in the acute phase of experimental colitis treated with Saccharomyces boulardii," Digestive Diseases and Sciences, vol. 55, no. 9, pp. 2498-2504, 2010.

[84] D. R. Mack, "Probiotics in inflammatory bowel diseases and associated conditions," Nutrients, vol. 3, no. 2, pp. 245-264, 2011.

[85] P. Gupta, H. Andrew, B. S. Kirschner, and S. Guandalini, "Is Lactobacillus GG helpful in children with Crohn's disease? Results of a preliminary, open-label study," Journal of Pediatric Gastroenterology and Nutrition, vol. 31, no. 4, pp. 453457, 2000.

[86] A. Ivarsson, O. Hernell, H. Stenlund, and L. A. Persson, "Breast-feeding protects against celiac disease," American Journal of Clinical Nutrition, vol. 75, no. 5, pp. 914-921, 2002.

[87] M. M. Tabbers, N. Boluyt, M. Y. Berger, and M. A. Benninga, "Nonpharmacologic treatments for childhood constipation: systematic review," Pediatrics, vol. 1128, no. 4, pp. 753-761, 2011.

[88] A. Chmielewska and H. Szajewska, "Systematic review of randomised controlled trials: probiotics for functional constipation," World Journal of Gastroenterology, vol. 16, no. 1, pp. 69-75, 2010.

[89] C. Koebnick, I. Wagner, P. Leitzmann, U. Stern, and H. J. F. Zunft, "Probiotic beverage containing Lactobacillus casei Shirota improves gastrointestinal symptoms in patients with chronic constipation," Canadian Journal of Gastroenterology, vol. 17, no. 11, pp. 655-659, 2003.

[90] M. Möllenbrink and E. Bruckschen, "Treatment of chronic constipation with physiologic Escherichia coli bacteria. results of a clinical study of the effectiveness and tolerance of microbiological therapy with the E. coli Nissle 1917 strain (Mutaflor)," Medizinische Klinik, vol. 89, no. 11, pp. 587-593, 1994.

[91] P. V. Guerra, L. N. Lima, T. C. Souza et al., "Pediatric functional constipation treatment with Bifidobacteriumcontaining yogurt: a crossover, double-blind, controlled trial," World Journal of Gastroenterology, vol. 17, no. 34, pp. 3916-3921, 2011.

[92] L. N. Bu, M. H. Chang, Y. H. Ni, H. L. Chen, and C. C. Cheng, "Lactobacillus casei rhamnosus Lcr35 in children with chronic constipation," Pediatrics International, vol. 49, no. 4, pp. 485-490, 2007.

[93] N. L. H. Bekkali, M. E. J. Bongers, M. M. Van den Berg, O. Liem, and M. A. Benninga, "The role of a probiotics mixture in the treatment of childhood constipation: a pilot study," Nutrition Journal, vol. 4, no. 6, article 17, 2007.

[94] A. Banaszkiewicz and H. Szajewska, "Ineffectiveness of Lactobacillus GG as an adjunct to lactulose for the treatment of constipation in children: a double-blind, placebo-controlled randomized trial," Journal of Pediatrics, vol. 146, no. 3, pp. 364-369, 2005.

[95] N. Vendt, H. Grünberg, T. Tuure et al., "Growth during the first 6 months of life in infants using formula enriched with Lactobacillus rhamnosus GG: double-blind, randomized trial," Journal of Human Nutrition and Dietetics, vol. 19, no. 1, pp. 51-58, 2006.

[96] N. Parassol, M. Freitas, K. Thoreux, G. Dalmasso, R. Bourdet-Sicard, and P. Rampal, "Lactobacillus casei DN114001 inhibits the increase in paracellular permeability of enteropathogenic Escherichia coli T84 cells," Research in Microbiology, vol. 156, no. 2, pp. 256-262, 2005.

[97] S. Resta-Lenert and K. E. Barrett, "Probiotics and commensals reverse TNF- $\alpha$ - and IFN- $\gamma$-induced dysfunction in human intestinal epithelial cells," Gastroenterology, vol. 130, no. 3, pp. 731-746, 2006.

[98] L. J. Fooks and G. R. Gibson, "Probiotics as modulators of the gut flora," British Journal of Nutrition, vol. 88, supplement 1, pp. S39-S49, 2002.

[99] H. Szajewska, A. Skórka, M. Ruszczyński, and D. Gieruszczak-Białek, "Meta-analysis: lactobacillus GG for treating acute diarrhoea in children," Alimentary Pharmacology \& Therapeutics, vol. 25, no. 8, pp. 871-881, 2007.

[100] H. Szajewska, A. Skórka, and M. Dylag, "Meta-analysis: Saccharomyces boulardii for treating acute diarrhoea in children," Alimentary Pharmacology and Therapeutics, vol. 25, no. 3, pp. 257-264, 2007.

[101] H. Szajewska and A. Skórka, "Saccharomyces boulardii for treating acute gastroenteritis in children: updated metaanalysis of randomized controlled trials," Alimentary Pharmacology and Therapeutics, vol. 30, no. 9, pp. 960-961, 2009.

[102] H. Szajewska, M. Wanke, and B. Patro, "Meta-analysis: the effects of Lactobacillus rhamnosus GG supplementation for the prevention of healthcare-associated diarrhoea in children," Alimentary Pharmacology and Therapeutics, vol. 34, no. 9, pp. 1079-1087, 2011.

[103] S. J. Allen, B. Okoko, E. Martinez, G. Gregorio, and L. F. Dans, "Probiotics for treating infectious diarrhoea," Cochrane Database of Systematic Reviews, no. 2, p. CD003048, 2004.

[104] B. C. Johnston, A. L. Supina, M. Ospina, and S. Vohra, "Probiotics for the revention of pediatric antibiotic-associated diarrhea," Cochrane Database of Systematic Reviews, no. 2, p. CD004827, 2007.

[105] B. C. Johnston, J. Z. Goldenberg, P. O. Vandvik, X. Sun, and G. H. Guyatt, "Probiotics for the prevention of pediatric antibiotic-associated diarrhea," Cochrane Database of Systematic Reviews, no. 11, p. CD004827, 2011.

[106] E. C. Dinleyici, M. Eren, M. Ozen, Z. A. Yargic, and Y. Vandenplas, "Effectiveness and safety of Saccharomyces boulardii for acute infectious diarrhea," Expert Opinion on Biological Therapy, vol. 12, no. 4, pp. 395-410, 2012.

[107] S. Guandalini, "Probiotics for prevention and treatment of diarrhea," Journal of Clinical Gastroenterology, vol. 45, pp. S149-S153, 2011.

[108] G. Musso, R. Gambino, and M. Cassader, "Obesity, diabetes, and gut microbiota: the hygiene hypothesis expanded?" Diabetes Care, vol. 33, no. 10, pp. 2277-2284, 2010. 
[109] R. Luoto, M. Kalliomäki, K. Laitinen, and E. Isolauri, "The impact of perinatal probiotic intervention on the development of overweight and obesity: follow-up study from birth to 10 years," International Journal of Obesity, vol. 34, no. 10, pp. 1531-1537, 2010.

[110] R. Luoto, K. Laitinen, M. Nermes, and E. Isolauri, "Impact of maternal probiotic-supplemented dietary counselling on pregnancy outcome and prenatal and postnatal growth: a double-blind, placebo-controlled study," British Journal of Nutrition, vol. 103, no. 12, pp. 1792-1799, 2010.

[111] E. Esteve, W. Ricart, and J. M. Fernández-Real, "Gut microbiota interactions with obesity, insulin resistance and type 2 diabetes: did gut microbiote co-evolve with insulin resistance?" Current Opinion Clinical Nutrition Metabolic Care, vol. 14, no. 5, pp. 483-490, 2011.

[112] M. Kalliomäki, S. Salminen, H. Arvilommi, P. Kero, P. Koskinen, and E. Isolauri, "Probiotics in primary prevention of atopic disease: a randomised placebo-controlled trial," The Lancet, vol. 357, no. 9262, pp. 1076-1079, 2001.

[113] S. Weston, A. Halbert, P. Richmond, and S. L. Prescott, "Effects of probiotics on atopic dermatitis: a randomised controlled trial," Archives of Disease in Childhood, vol. 90, no. 9, pp. 892-897, 2005.

[114] M. Viljanen, E. Savilahti, T. Haahtela et al., "Probiotics in the treatment of atopic eczema/dermatitis syndrome in infants: a double-blind placebo-controlled trial," Allergy, vol. 60, no. 4, pp. 494-500, 2005.

[115] T. Passeron, J. P. Lacour, E. Fontas, and J. P. Ortonne, "Prebiotics and synbiotics: two promising approaches for the treatment of atopic dermatitis in children above 2 years," Allergy, vol. 61, no. 4, pp. 431-437, 2006.

[116] V. Rosenfeldt, E. Benfeldt, S. D. Nielsen et al., "Effect of probiotic Lactobacillus strains in children with atopic dermatitis," Journal of Allergy and Clinical Immunology, vol. 111, no. 2, pp. 389-395, 2003.

[117] C. Pelucchi, L. Chatenoud, F. Turati et al., "Probiotics supplementation during pregnancy or infancy for the prevention of atopic dermatitis: a meta-analysis," Epidemiology, vol. 23, no. 3, pp. 402-414, 2012.

[118] S. C. Velaphi, P. A. Cooper, K. D. Bolton et al., "Growth and metabolism of infants born to women infected with human immunodeficiency virus and fed acidified wheyadapted starter formulas," Nutrition, vol. 24, no. 3, pp. 203211, 2008.

[119] Z. Weizman, G. Asli, and A. Alsheikh, "Effect of a probiotic infant formula on infections in child care centers: comparison of two probiotic agents," Pediatrics, vol. 115, no. 1, pp. 5-9, 2005.

[120] J. Maldonado, F. Lara-Villoslada, S. Sierra et al., "Safety and tolerance of the human milk probiotic strain Lactobacillus salivarius CECT5713 in 6-month-old children," Nutrition, vol. 26, no. 11-12, pp. 1082-1087, 2010.

[121] O. Brunser, G. Figueroa, M. Gotteland et al., "Effects of probiotic or prebiotic supplemented milk formulas on fecal microbiota composition of infants," Asia Pacific Journal of Clinical Nutrition, vol. 15, no. 3, pp. 368-376, 2006. 


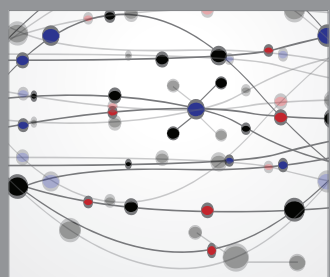

The Scientific World Journal
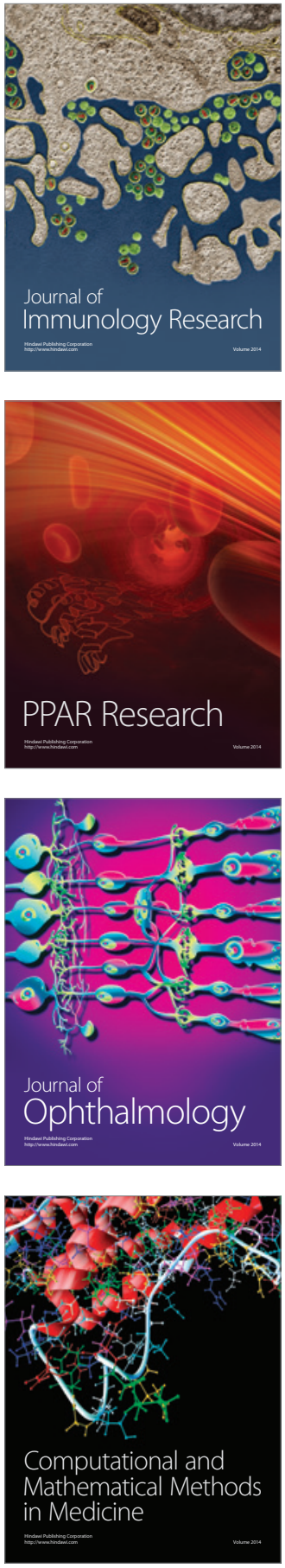

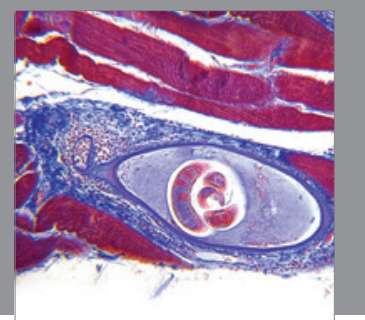

Gastroenterology

Research and Practice
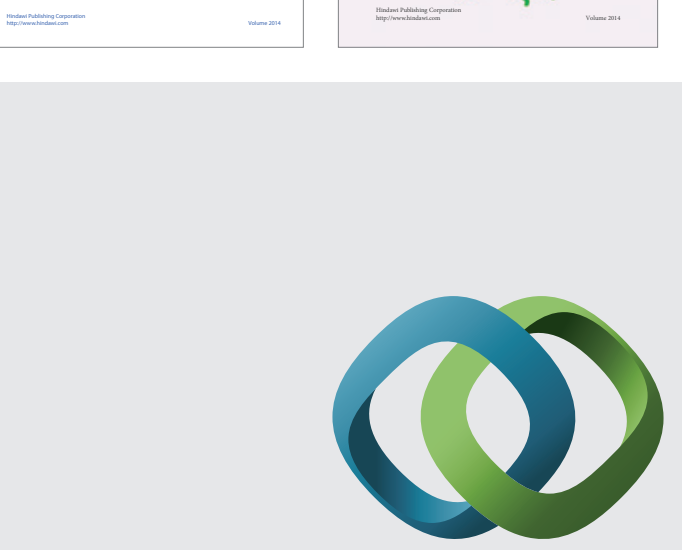

\section{Hindawi}

Submit your manuscripts at

http://www.hindawi.com
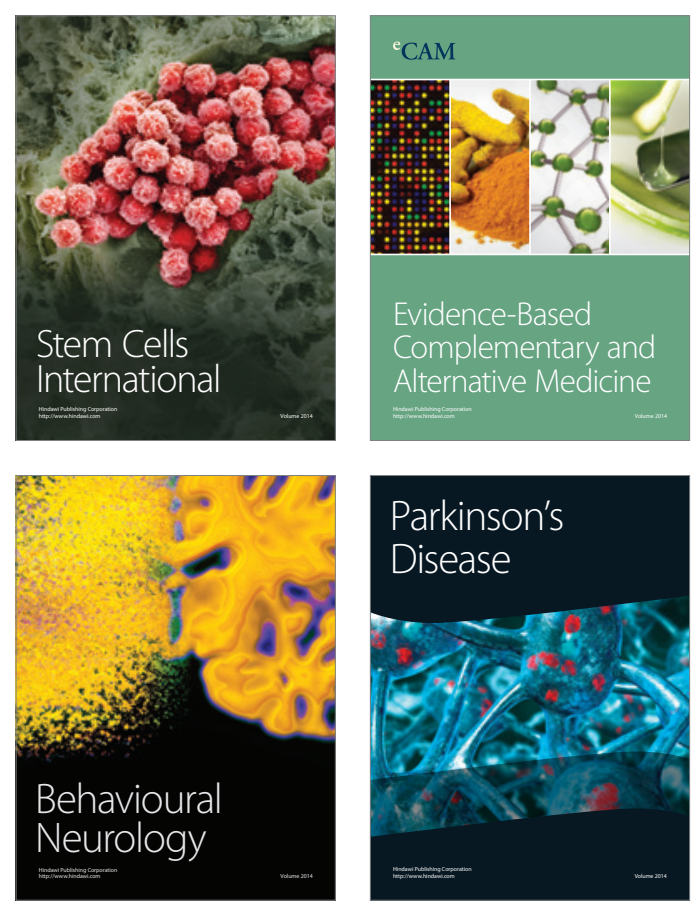

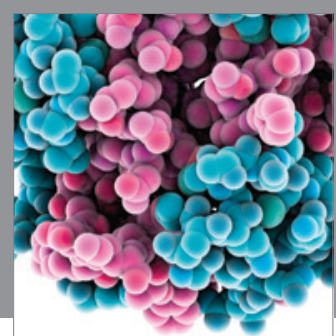

Journal of
Diabetes Research

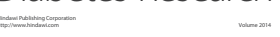

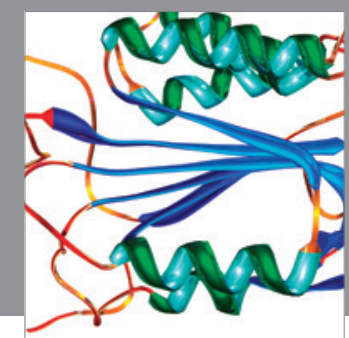

Disease Markers
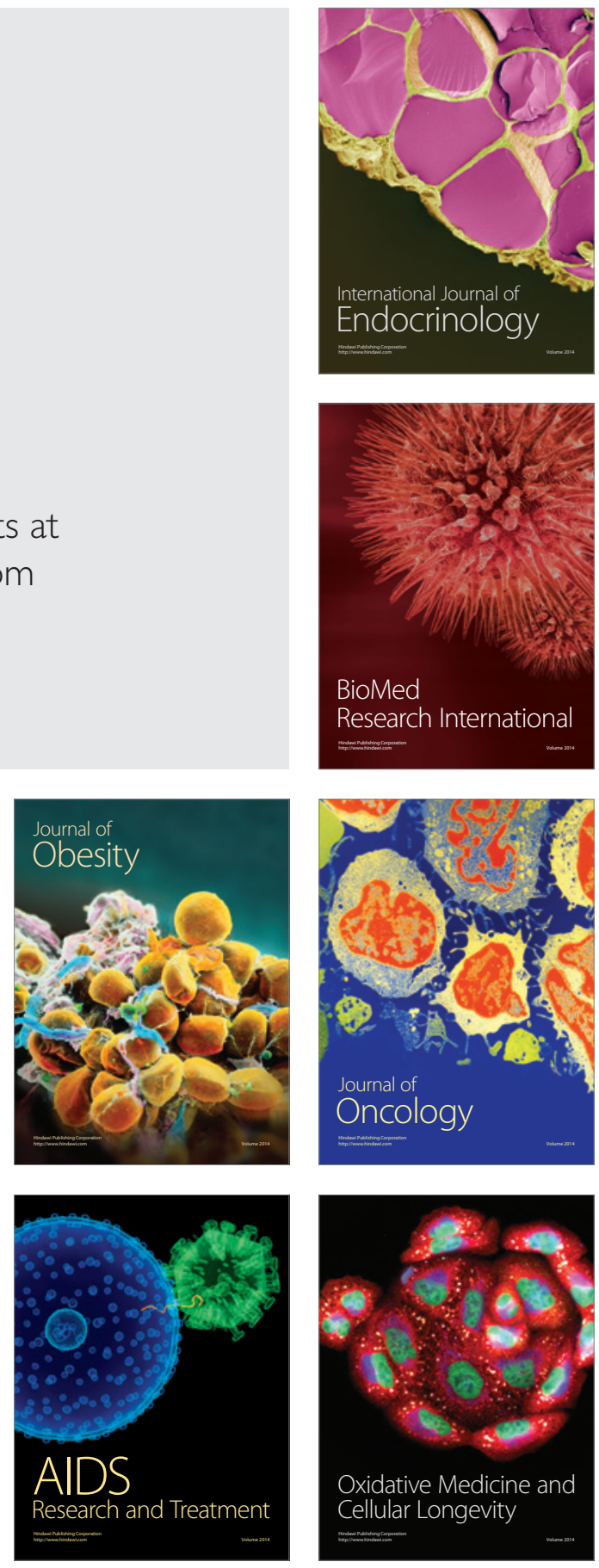